\title{
DO PENSAMENTO BENVENISTIANO À PRÁTICA DE REVISÃO TEXTUAL: REFLEXÕES TEÓRICAS PERTINENTES AO REVISOR
}

\section{DEL PENSAMIENTO BENVENISTIANO A LA PRÁCTICA DE REVISIÓN TEXTUAL: REFLEXIONES TEÓRICAS PERTINENTES AL REVISOR}

FROM THE BENVENISTIAN THOUGHT TO THE PRACTICE OF TEXTUAL REVIEW: THEORETICAL REFLECTIONS RELEVANT TO THE REVIEWER

Aroldo Garcia dos Anjos*

Daiane Neumann** Mayara Espindola Lemos*** Universidade Federal de Pelotas

RESUMO: Este trabalho parte do pensamento benvenistiano, considerando sobretudo os estudos de Émile Benveniste acerca do sentido, da significância e dos níveis semiótico e semântico, como conceitos relevantes para o conhecimento do revisor de textos e, consequentemente, para a prática de revisão. Para tanto, iniciamos nosso estudo expondo um pequeno panorama do atual cenário da profissão de revisor. Na sequência, discutiremos algumas reflexões de Benveniste que julgamos relevantes para a proposta deste artigo, trazendo como suporte também pesquisas realizadas com base na obra do linguista, como as de Dessons (2006) e Messa e

\footnotetext{
* Mestre em Letras pela Universidade Federal de Pelotas. Graduado em Letras Alemão e Português pela Universidade do Valedos Sinos. Professorde Alemãoetradutor. E-mail: aroldodosanjos@gmail.com. 
Teixeira (2015). Por fim, relacionamos os estudos do linguista com a atividade de revisão textual, intencionando contribuir para reflexões que possam enriquecer essa área.

PALAVRAS-CHAVE: Revisão de textos. Benveniste. Semiótico e semântico. Sentido. Significância.

RESUMEN: Este trabajo parte del pensamiento benvenistiano, considerando principalmente los estudios de Émile Benveniste acerca del sentido, de la significancia y de los niveles semiótico y semántico, como conceptos relevantes para el conocimiento del revisor de textos y, consecuentemente, para la práctica de revisión. Para ello, empezamos nuestro estudio presentando un breve panorama del escenario actual de la profesión de revisor. En la secuencia, discutiremos algunas reflexiones de Benveniste que consideramos relevantes para la propuesta de este artículo, trayendo como soporte también investigaciones realizadas a partir de la obra del lingüista, como las de Dessons (2006) y Messa y Teixeira (2015). Por último, relacionamos los estudios del lingüista con la actividad de revisión textual, con la intención de contribuir a reflexiones que puedan enriquecer esta área.

PALABRAS CLAVE: Revisión de textos. Benveniste. Semiótico y semántico. Sentido. Significancia.

ABSTRACT: This paper is based on Benvenistian thinking, especially considering the studies of Émile Benveniste about meaning, significance and semiotic and semantic levels as relevant concepts for reviewers and, as a consequence, to the practice of text revision. In the first section, we give a brief overview of the current scenario of the reviewing profession. Afterwards, we discuss some reflections of Benveniste that we consider relevant to the purpose of this article, bringing up as a theoretical support research based on the work of the linguist, such as that from Dessons (2006) and Messa and Teixeira (2015). Finally, we relate the studies of the linguist to the activity of text revision, intending to contribute to this discussion.

KEYWORDS: Text revision. Benveniste. Semiotic and semantic. Meaning. Significance.

\section{INTRODUÇÃO}

No presente trabalho, discutimos as possíveis contribuições do pensamento de Émile Benveniste para a área de revisão textual, focando seus estudos sobre o sentido, a significância e os níveis semiótico e semântico. Para tanto, apresentamos uma proposta de leitura de sua obra, buscando questões pertinentes à prática de revisar textos. Ainda que as obras Problemas de linguística geral I e II tenham como objetivo levantar questionamentos sem a pretensão de um fechamento, elas propõem discussões que propiciaram desdobramentos posteriores. Assim, partimos do entendimento de que há nelas também reflexões pertinentes ao revisor.

Nas duas obras de Benveniste, observamos a constante preocupação do linguista no que tange às relações existentes entre língua/linguagem, homem, sociedade e cultura, aspectos esses que julgamos importantes e que, portanto, devem ser levados em consideração pelo profissional de revisão. No entanto, limitamos este estudo a um recorte que abrange o posicionamento de Benveniste acerca do sentido, da significância, do semiótico e do semântico, partindo do pressuposto de que essas são concepções que servem de ponto de partida para um aprofundamento dos estudos do linguista, a fim de contribuir com o campo do saber a que dedicamos a presente reflexão.

Desse modo, para propor o início de uma discussão sobre as contribuições dos estudos de Benveniste para a área de revisão de textos, num primeiro momento, situamos o atual cenário da profissão de revisor; na sequência, apresentamos reflexões de Benveniste com vistas a elucidar nosso estudo; posteriormente, relacionamos as ideias do linguista com a atividade de revisão, salientando as contribuições daquelas ao ofício de revisar textos.

\section{O ATUAL CENÁRIO DA REVISÃO DE TEXTOS}

O papel social do revisor faz-se importante e necessário devido ao alcance dos mais variados textos na sociedade. Há uma vasta possibilidade de atuação para o revisor, podendo ele escolher dedicar-se ao trabalho com um gênero textual específico ou com vários deles. Dado o grande alcance que um texto pode ter após passar pelas mãos do revisor, esse profissional precisa adquirir sólidos 
conhecimentos, que ultrapassam o domínio da norma culta da língua. Assim, cabe ao profissional estar a par do que ocorre na sociedade através da observação dos diferentes discursos, que sustentam os aspectos culturais e as visões de mundo presentes na construção dos sujeitos e se revelam como efeitos de sentido nos textos. Conforme Benveniste (1976, p. 32),

A cultura define-se como conjunto muito complexo de representações, organizadas por um código de relações e de valores: tradições, religião, leis, política, ética, artes, tudo isso de que o homem, onde quer que nasça, será impregnado no mais profundo da sua consciência, e que dirigirá o seu comportamento em todas as formas da sua atividade $[\ldots]$.

É importante destacar que a atividade de revisar textos é tão antiga quanto o uso da escrita e foi evoluindo com o passar do tempo. Assim, a profissão de revisor de textos foi considerada como tal recentemente e, aos poucos, vem ganhando espaço no mercado de trabalho. É necessário salientar ainda que, devido ao crescimento da promoção da área de revisão textual na última década, através de graduação, especialização e de cursos livres presenciais e a distância, as pesquisas direcionadas a esse campo tornaram-se mais numerosas, mas ainda há muito o que ser discutido sobre sua prática, tanto no que tange às questões trabalhistas quanto à teoria que sustenta o fazer desse profissional.

Em razão disso, há certa dificuldade em definir os currículos dos cursos voltados à revisão, uma vez que as exigências dessa profissão vão muito além do conhecimento da estrutura da língua e das noções gramaticais. Assim, em se tratando do conhecimento teórico necessário ao revisor, acreditamos que as correntes linguísticas que não se prendem somente aos aspectos estruturais e formais que compõem um texto podem trazer um suporte aos estudos e possibilitar reflexões que vão ao encontro do trabalho de revisão de textos.

O campo de trabalho do revisor de textos exige flexibilidade na análise das produções textuais para que ele possa transitar pelos diferentes gêneros textuais, pois cada gênero tem suas peculiaridades, e o profissional pode tanto optar por trabalhar com um como com vários deles. Essa habilidade também é necessária porque os textos, para além dos gêneros aos quais pertencem, são escritos por indivíduos diversos, que estão inseridos na sociedade em situações que se diferem, em comunidades, culturas, modos de vida variados, principalmente no contexto em que vivemos, no qual o desenrolar dos acontecimentos se dá de forma muito rápida, e a informação está cada vez mais ao alcance de todos.

Compreendemos, assim, que uma produção textual é também o produto de todas essas condições, diz sobre o autor, sobre o mundo, porque, como veremos na sequência, a linguagem os constitui. E, em razão disso, o enunciado pode se apresentar de diferentes maneiras, cabendo ao revisor ter o domínio sobre essa pluralidade de possibilidades do dizer, para então atuar sobre elas.

Diante desse panorama da revisão textual, entendemos que o revisor é um profissional em constante crescimento intelectual, uma vez que necessita estar sempre atualizado sobre as mudanças que ocorrem na sociedade, sobre as novas formas de olhar para o mundo. Além disso, o profissional da área deve compreender que existem diferentes culturas, visões de mundo e subjetividades, e todas precisam ser respeitadas quando se manifestam. É essencial ao revisor de textos ter senso de coletividade e de respeito ao próximo, pois ele lida com ideias, subjetividades e posicionamentos que emergem dos textos com os quais trabalha.

É nesse contexto de atuação do revisor de textos que inserimos, dentre as muitas possibilidades de estudo, o pensamento de Émile Benveniste no que concerne ao sentido, à significância e aos níveis semiótico e semântico. Nas obras Problemas de linguística geral I e Problemas de linguística geral II, Benveniste dedica-se às questões de ordem linguística, levantando proposições e discussões no que tange ao sentido na linguagem. Com vistas ao desenvolvimento deste trabalho, tomamos como base, em especial, os textos: $A$ natureza dos pronomes (1956), Da subjetividade na linguagem (1958), Vista d'olhos sobre o desenvolvimento da linguística (1963), A forma e o sentido na linguagem (1967), Estruturalismo e linguística (1968) e Semiologia da língua (1969).

Para dar continuidade à reflexão aqui proposta, passaremos, na próxima seção, à reflexão sobre o pensamento benvenistiano, bem como à discussão de alguns conceitos caros à sua teorização. 


\section{O PENSAMENTO BENVENISTIANO}

Para Benveniste (1976), a linguagem não é um instrumento porque não é construída de forma dissociada do homem, ela é natural a ele, ou seja, constitui-se e se constrói com ele. Sob o olhar do linguista, não existe acesso direto ao mundo, ou seja, o reproduzimos através do simbólico. Em Vista d’olhos sobre o desenvolvimento da linguística, Benveniste diz que "a linguagem reproduz a realidade" (1976, p. 285). No original em francês, percebe-se como o autor destaca o prefixo para realçar a ideia de uma nova ação: "Le langage re-produit la réalité". Trata-se, pois, de produzir a realidade novamente através da linguagem.

Esse ato sempre novo de criação passa, no entanto, pela língua, pois, segundo o autor, "a linguagem reproduz o mundo, mas submetendo-o à sua própria organização" (1976, p. 26). Assim, culturas diferentes têm visões de mundo também diferentes, uma vez que cada língua recorta o pensamento de modo diverso. Isso porque percebemos o mundo a partir do simbólico e, portanto, da linguagem. É a linguagem que funda o mundo, consequentemente, ele só é construído através dela. E o homem, por sua vez, só se propõe como sujeito ao dizer-se e dizer o mundo através da linguagem. Paralelamente à noção de forma, a análise de Benveniste considera, assim, necessariamente, a função da linguagem. Essa noção da linguagem como constituidora da cultura é retomada em Estruturalismo e linguística:

[...] nenhuma língua é separável de uma função cultural. Não há aparelho de expressão tal que se possa imaginar que um ser humano seja capaz de inventá-la sozinho [...]. É o poder de ação, de transformação, de adaptação, que é a chave da relação humana entre a língua e a cultura, uma relação de integração necessária [...]. (BENVENISTE, 1989, p. 24)

Sob esse raciocínio, o homem constitui-se como sujeito na linguagem a partir do uso do pronome "eu", preenchido pela pessoa que fala e postulante de um "tu”, figura necessária da alocução. A condição de diálogo aponta para o caráter intersubjetivo da linguagem, sem o qual não se poderia pensar a constituição humana. A linguagem é não apenas condição, como também um meio para essa constituição. Assim, a inserção do homem na língua, a passagem de locutor a sujeito, é o que se denomina subjetividade. Segundo Benveniste (1976, p. 286, grifos do autor), a subjetividade

[...] é a capacidade do locutor para se propor como "sujeito". Define-se não pelo sentimento que cada um experimenta de ser ele mesmo (esse sentimento, na medida em que podemos considerá-lo, não é mais que um reflexo) mas como a unidade psíquica que transcende a totalidade das experiências vividas que reúne, e que assegura a permanência da consciência. [...] não é mais que a emergência no ser de uma propriedade fundamental da linguagem.

Nessa perspectiva, a subjetividade é decorrente do modo como o locutor se apropria da língua, apresentando-se como sujeito, remetendo a si mesmo como "eu" em seu discurso e organizando as relações espaciais e temporais, a instância de enunciação da qual ele é o centro de referência. Assim, o ato de apropriação da forma "eu" é fundamento da subjetividade, e a linguagem, sua possibilidade. Como Benveniste já apontara em a Natureza dos pronomes, essa propriedade da linguagem de propor um signo móvel "fundamenta o discurso individual, em que cada locutor assume por sua conta a linguagem inteira" (BENVENISTE, 1976, p. 281). Logo, a subjetividade não existiria sem a língua, e é essa que permite que exista o sujeito, como um efeito de sentido.

Conforme explicam Messa e Teixeira (2015, p. 104), para Benveniste, “[...] significar está no fundamento da linguagem, que é dotada dessa faculdade antes mesmo de servir para comunicar". Desse modo, completam as autoras, "o sujeito benvenistiano não é anterior à língua, mas resulta da enunciação. Ele só existe pelo fato de falar, emergindo como efeito, na e pela linguagem, radicalmente atravessado pela cultura" (MESSA; TEIXEIRA, 2015, p. 107, grifo das autoras).

No pensamento de Benveniste, a linguagem é apresentada como condição da existência do homem, sempre referida ao outro. Sob as bases dessa visão de linguagem, no âmbito da semântica da enunciação, a significação implica a relação que a linguagem instaura entre o enunciador, o mundo, os outros sistemas simbólicos e a sociedade. (MESSA; TEIXEIRA, 2015, p. 107) 
Aprofundando a discussão sobre a significação, em A forma e o sentido na linguagem, Benveniste discute a impossibilidade da definição do sentido a priori. O sujeito, por conseguinte, é um constante devir. Por isso, é preciso observar o texto por ele mesmo. Para o linguista, é importante pensar como o discurso constrói o mundo, a realidade, pois, sob sua visão, significar é condição para a sociedade e para a humanidade (BENVENISTE, 1989, p. 222).

No texto em questão, para discutir o problema da significação, Benveniste busca reinterpretar, no funcionamento da língua e de modo integrado, as noções de sentido e de forma. Podemos constatar que o autor parte da noção de sistema para pensar o sentido. Desse modo, reflete sobre como as unidades do sistema significam no uso. Sob o olhar de Benveniste, metodologicamente, a língua se divide em semiótico e semântico. Na noção de semiótico, encontra-se a língua enquanto sistema de signos, assim, observam-se as unidades para pensar o todo. Nesse domínio, Benveniste diz que "significar é ter um sentido, nada mais" (1989, p. 227). Isso quer dizer que o signo, tal qual cunhado por Ferdinand de Saussure, deve ser compartilhado socialmente, pois o sistema se dá pelo reconhecimento de suas unidades. O signo, composto de significante e significado, tem por característica ser distintivo em relação aos demais signos da língua e possuir valor sempre genérico.

Partindo da noção de arbitrário de Saussure, descrita no Curso de Linguística Geral (2012), Benveniste (1989, p. 227-228, grifos do autor) ressalta que

[...] tudo o que é do domínio do semiótico tem por critério necessário e suficiente que se possa identificá-lo no interior e no uso da língua. Cada signo entra numa rede de relações e de oposições com os outros signos que o definem, que o delimitam no interior da língua. Quem diz "semiótico" diz "intralinguístico". Cada signo tem de próprio o que o distingue dos outros signos. Ser distintivo e ser significativo é a mesma coisa.

A noção de semântico trata do nível da frase, logo, do discurso. O semântico parte do todo para observar a unidade. Para Benveniste (1989), é o todo que produz sentido. Nessa perspectiva, a frase está ligada ao aqui e agora, ela possui o elemento da subjetividade, que é algo que não cabe no sistema da língua. O nível semântico vê a língua em seu "emprego e ação", como mediadora entre "o homem e o homem, entre o homem e o mundo, entre o espírito e as coisas, transmitindo a informação, comunicando a experiência [...], organizando toda a vida dos homens" (BENVENISTE, 1989, p. 229). O linguista também ressalta que

[... a semântica é o "sentido" resultante do encadeamento, da apropriação pela circunstância e da adaptação dos diferentes signos entre eles. Isto é absolutamente imprevisível. É a abertura para o mundo. Enquanto que o semiótico é o sentido fechado sobre si mesmo e contido de algum modo em si mesmo. (BENVENISTE, 1989, p. 21, grifo do autor)

No entanto, forma e sentido não devem ser dissociados. É dessa indissociabilidade entre ambos que o texto, enquanto unidade, constrói sua significância. E, sendo o texto um encadeamento de ideias, cabe destacar o que Benveniste (1989, p. 230, grifos do autor) salienta a respeito da frase: "[...] o sentido da frase é de fato a ideia; esse sentido se realiza formalmente na língua pela escolha, pelo agenciamento de palavras, por sua organização sintática, pela ação que elas exercem umas sobre as outras”.

Para Benveniste, momento, lugar e interlocutores determinam a situação à qual o enunciado se refere e que vai lhe atribuir valor e significado. A frase é sempre um evento particular, "um acontecimento que desaparece" (1989, p. 231). Há, desse modo, dois domínios que atuam constantemente na língua. Esses sistemas se sobrepõem no uso, sendo que o semiótico se encontra na base do semântico.

Por essa perspectiva, o texto produz a realidade. Com base no pensamento do linguista, o ato da produção de um texto significa, ao mesmo tempo, a construção do pensamento, a construção de ideias. Assim, sob essa ótica, o sujeito, no ato de escrever um texto, cria a todo instante novas ideias, consequentemente, dotando de sentido sua produção. Ao final, no seu todo, tem-se uma rede de significância, constituindo uma realidade. Assim, "[...] é o todo do discurso que produz as relações que podem ser construídas a partir da leitura" (NEUMANN, 2016, p. 63). 
Em Semiologia da língua, Benveniste procura delimitar o que é próprio da língua ao compará-la com outros sistemas de signos. Para Saussure, inseridas no campo da Semiologia, estariam todas as ciências que estudam os diferentes sistemas de signos, entre elas a Linguística. Assim, Saussure teria marcado a relação necessária da Linguística com a Semiologia, ao eleger a língua como o mais importante dos sistemas de signos, mas não teria definido de que natureza é essa relação. É objetivo de Benveniste, nesse texto, tratar da relação semiótica da língua em relação aos demais sistemas. Isso leva o autor a definir a língua como o interpretante por excelência da sociedade, por sua capacidade de categorizar o mundo e de interpretar, inclusive, a si mesma.

O que nos interessa nessa discussão é o fato de que a língua é o único sistema que interpreta todos os outros na sociedade, pois “[...] toda semiologia de um sistema não-linguístico deve pedir emprestada a interpretação da língua" (BENVENISTE, 1989, p. 61). Somente temos acesso a tudo a nossa volta pela língua. O texto é, portanto, uma manifestação do sujeito por meio da língua e carrega a sua subjetividade.

Benveniste conclui que a língua comporta dois domínios distintos, cada um dos quais deve possuir o seu aparelho conceitual. Tratase, dessa forma, de tentar superar o impasse criado pela noção de signo. O autor propõe duas vias para essa ultrapassagem. A primeira é de caráter intralinguístico, chamada semântica, que objetiva analisar a dimensão de significância do discurso. A segunda seria a constituição de uma metassemântica, que estudaria a significância em textos e em obras literárias. A metassemântica trataria, portanto, da semântica do homem que fala e, nesse ato de comunicar, ressignificaria constantemente a língua. Desse modo, estudaria as formas complexas do discurso (MESSA; TEIXEIRA, 2015). Essa nova ciência não chegou a ser desenvolvida por Benveniste, porém, alguns de seus estudiosos tentaram desenvolvê-la a partir das sugestões do linguista, o que deu margens a muitas vertentes.

Destacadas algumas noções que são importantes para o debate que aqui propomos, passaremos, em seguida, para a discussão acerca das contribuições que o pensamento benvenistiano pode trazer para a atividade de revisão textual.

\section{CONTRIBUIÇÕES BENVENISTIANAS À ATIVIDADE DE REVISÃO TEXTUAL}

Após expormos uma síntese da reflexão benvenistiana acerca das noções de sentido, significância e semiótico e semântico, trazemos, na sequência, algumas discussões que podem ser úteis para a área de revisão textual, de modo a contemplar os estudos nesse campo do saber. Acreditamos que essa relação pode trazer significativas contribuições aos revisores de textos, tanto aqueles em formação quanto os profissionais que já possuem experiência no mercado de trabalho.

\subsection{O TEXTO PELO TEXTO: SENTIDO E SIGNIFICÂNCIA SOB O VIÉS DA REVISÃO DE TEXTOS}

Se, como acredita Benveniste, a linguagem significa o mundo por estar na natureza do homem, que somente é sujeito na e através dela, seria pertinente, portanto, revisar um texto de modo a perceber o seu sentido a partir da análise de como o sujeito se constrói em seu dizer, considerando que a forma do dizer não pode ser dissociada daquilo que é dito. Dessa forma, trataríamos de observar como o sistema de signos se atualiza em situações de uso, pois a língua se manifesta pela enunciação, sempre subjetiva e particular. Isso não significa que os aspectos formais não sejam relevantes. No entanto, é importante considerar a emergência do todo do texto, que é dotado de significação e responsável por atribuir a significância das partes.

Diante dessa perspectiva, podemos dizer ainda que o texto constitui o mundo, ou seja, cria o real. Isso porque, conforme o pensamento de Benveniste, o sujeito se constitui na e pela relação com a sociedade e vice-versa. Essa relação se dá, necessariamente, através da língua, pois é ela que "[...] constitui o que mantém juntos os homens, o fundamento de todas as relações que por seu turno fundamentam a sociedade" (BENVENISTE, 1989, p. 63).

Não há emprego de "eu" que não seja dirigido a alguém. O "tu" é parte integrante da enunciação. A condição de diálogo põe em jogo "eu" e "tu" como figuras necessárias, origem e fim da enunciação. A intersubjetividade é, pois, a possibilidade de subjetividade, uma vez que, como afirma Benveniste (1976, p. 286), “a consciência de si mesmo só é possível se experimentada por contraste”. Na ideia 
de intersubjetividade encontramos a de sociedade, visto que o outro é condição constitutiva do sujeito e de seu discurso. Esse vínculo íntimo se marca na língua através da interdependência dos pronomes, pela relação complementar entre "eu" e "tu” e pela relação de oposição entre "eu" e "ele".

Quando um sujeito fala sobre si ou sobre algo, ele apresenta um ponto de vista em relação a si mesmo, ao outro e àquilo sobre o que fala, ou seja, dá significação a si, ao outro e ao objeto em foco. Falar, assim, sempre é falar de. Dessa forma, partindo de Benveniste, é preciso analisar o texto pelo texto, ou seja, observar como os sentidos são produzidos nos discursos, já que o sujeito e a linguagem são um constante devir. Para o linguista sírio, a linguagem é construída para significar, ela constitui a sociedade, logo, o homem é construído de sentido. Nesse contexto, a subjetividade do texto deve ser percebida e preservada pelo revisor. Isso porque ela mostra como o texto funciona para produzir sentidos. Ao revisor, perceber a subjetividade, ainda que nem sempre se apresente através de marcas explícitas, é muito importante, dado que a observância do sujeito da linguagem significa buscar preservar sentidos, pois o texto, em função de sua circulação, atua como fonte de informação, conhecimento.

Consideramos, ainda, que o "tu" também possui papel importante na constituição do texto e deve ser considerado no trabalho de revisão. Pode-se afirmar que para além dos sentidos presentes na produção textual advindos de quem escreve e das diferentes vozes que a compõem, outros sentidos surgem a partir da imagem do "tu" que se constrói no e pelo texto. Ser sensível à preservação desse "tu" constituído no texto também é tarefa do revisor.

Podemos assim refletir sobre o papel do revisor, que vai além da busca por adequação dos aspectos gramaticais, do sistema da língua e abrange a sensibilidade de compreender a subjetividade do texto, o sentido único que se está construindo a partir daquela relação forma-sentido, particular daquele texto. Desse modo, levamos em conta a forma como quem escreve se propõe como "sujeito" e como se constrói o "tu" que advém do texto. Analisamos, pois, os elementos que fazem a produção textual significar, porque a ela pertencem e, nela, enquanto manifestação da língua, se constituem, como cultura e sociedade. Desse modo, na prática de revisão textual, quanto maior for a capacidade do profissional de compreender o sentido permeado na escolha das palavras e na forma como se estrutura o texto, mais adequado este estará para entrar em circulação.

\subsection{NOÇÃO DE SEMIÓTICO E SEMÂNTICO}

A revisão não se dá somente na linearidade do texto, há elementos que se articulam na sua totalidade e requerem a leitura atenta do revisor. Muito se pensou, e quem não conhece a atividade ainda pensa, que o trabalho de revisar se baseia na correção gramatical ou a tem como ponto de partida. Neste trabalho, contudo, apoiamo-nos nos conceitos de semiótico e semântico de Benveniste com o intuito de levantar a questão acerca da complexidade da tarefa do revisor, pois, como alerta o linguista, há indissociabilidade entre esses níveis.

Na concepção de semiótico de Benveniste, podemos inserir a análise gramatical, imprescindível à revisão. Sabemos não ser possível reduzir o semiótico da língua à gramática, nem mesmo considerá-lo em separado do semântico, no entanto, para o revisor, metodologicamente, pode-se conceber o nível semiótico como o lugar da análise mais formal da produção textual. Pensar no semiótico é, pois, considerar o que há de compartilhado e reiterável da língua, é olhar para o signo enquanto virtualidade.

No entanto, para Benveniste, os domínios se sobrepõem: sobre o fundamento semiótico, há a construção de uma semântica própria, relativa ao domínio semântico. Esse processo, o qual Benveniste chama de sintagmatização, implica considerar que, no uso, "[...] cada palavra não retém senão uma pequena parte do valor que tem enquanto signo" (BENVENISTE, 1989, p. 234). Considera-se, assim, que a palavra é sempre particular.

Desse modo, nos textos, observamos os morfemas, os itens lexicais, as sentenças, cada uma delas significando de maneira particular. Observamos, portanto, como o locutor se apropria da língua enquanto sistema e a sintagmatiza dentro de um quadro de referência próprio. Para Benveniste (1976, p.132), “[...] a palavra é um constituinte da frase, efetua-lhe a significação; mas não aparece necessariamente na frase com o sentido que tem como unidade autônoma. A palavra pode assim definir-se como a menor unidade 
significante livre susceptível de efetuar uma frase [...]". A partir desse pensamento, podemos refletir sobre a necessidade, para a revisão textual, de compreender como um texto funciona, como as palavras estão organizadas, dotadas de significância, para formar uma rede de sentidos.

Em se tratando da noção de semântico que, segundo Benveniste, debruça-se sobre a análise da frase, ou seja, do discurso, o revisor observa o texto como um todo. É a produção toda do discurso que cria a subjetividade, pois ela existe até mesmo quando não há marcas evidentes no texto. Logo, para o linguista, não existe língua sem subjetividade, nem subjetividade sem língua. E, sob essa perspectiva, compreendemos o sentido que o conjunto de signos escolhidos pelo autor produz. Isso porque a forma muda o sentido, e a mudança de sentido requer alteração na forma.

Na revisão de um texto - independentemente do gênero a que ele pertence, mas principalmente no gênero literário -, nem sempre a forma pode ser modificada, pois é ela que pode estar garantindo o sentido que o autor intenciona dar à sua produção. Sob esse viés, o que na gramática da língua é interpretado muitas vezes como um desvio, pode ser crucial para a construção do sentido de um texto. Cabe ressaltar aqui que não só a significância das palavras influencia no texto, como também a pontuação escolhida é carregada de significação. Assim, partimos do todo para analisar como a forma está funcionando para produzir sentido, para compreender a importância dada a cada palavra, sua significância particular de um texto particular.

Em função da constante produção de ideias que se faz presente ao escrever, é comum que algumas delas não fiquem perceptíveis, posteriormente, ao leitor. Por isso a importância do trabalho do revisor como mediador entre locutor e interlocutor, com a responsabilidade de tornar essas ideias mais claras na atividade de leitura, garantindo a circulação das diversas formas de construir e significar o mundo. Conforme afirma Benveniste (1989, p. 18), "[...] todo homem inventa sua língua e a inventa durante toda sua vida. E todos os homens inventam sua própria língua a cada instante e cada um de uma maneira distintiva, e a cada vez de uma maneira nova".

Desse modo, entendemos que a produção textual tem seu início na constituição do "eu" que a produz, que a carrega de significação, passa pela mediação da subjetividade do revisor, que busca reafirmar os sentidos nela contidos e, finalmente, chega à subjetividade do interlocutor que, a cada nova leitura, perceberá um novo significar no texto. Neumann (2016, p. 66) contempla essa ideia ao afirmar que "o discurso é concebido como um sistema de valores que não é fechado, nem acabado, pois a produção de significância é infinita. Há sempre a possibilidade de se construir novos sentidos, novas leituras.". Sendo assim, a circulação de um texto na sociedade proporciona, a cada nova leitura, um novo sentido, logo, infinitas possibilidades de sentidos, dependendo dos indivíduos, de suas subjetividades, bem como do contexto social (momento, lugar, interlocutores) e histórico nos quais essas leituras são realizadas.

\section{CONSIDERAÇÕES FINAIS}

O revisor, enquanto profissional capacitado para intervir em produções textuais, leva em conta o contexto presente nos textos. Messa e Teixeira (2015) salientam que a semântica da enunciação de Benveniste estabelece uma relação mútua entre linguagem, homem, cultura e sociedade. Esses conceitos interessam ao revisor, uma vez que na sua prática é necessário voltar o olhar a esse todo que envolve a construção do texto.

Acreditamos que a metassemântica proposta por Benveniste, se desenvolvida, é uma das abordagens cujo estudo seria de grande valia enquanto apoio teórico para o revisor, tendo em vista que o texto seria analisado enquanto unidade, o discurso em seu todo, foco do trabalho desse profissional. A partir da visão de uma metassemântica proposta por Benveniste, Neumann (2016, p. 63) destaca que

[...] o texto e a obra são considerados como uma unidade que produz a sua própria significância através de relações paradigmáticas e sintagmáticas que emergem dessa unidade. Tais relações passam por todos os 
elementos da linguagem, pela prosódia, pela acentuação, pela sintaxe, pela morfologia, por cada vogal, por cada consoante. Ou seja, é o todo do discurso que produz as relações que podem ser construídas a partir da leitura.

Nosso trabalho se limitou, portanto, a uma pequena reflexão acerca do pensamento de Benveniste, sem a pretensão de ser conclusivo, ao contrário, com a intenção de que se possa, na posteridade, desenvolverem-se sólidos estudos acerca da atividade de revisão de textos. Entendemos que a leitura das diferentes vertentes da Linguística nos proporciona uma consistência teórica que atua de forma positiva na formação do revisor. Assim, vemos este estudo como conteúdo relevante, que contribui para a atividade desse profissional diante dos textos.

Concluímos, portanto, que a visão de Benveniste sobre as relações existentes entre língua/linguagem, homem, sociedade e cultura, quando observada sob o viés da revisão textual, é parte de um constructo teórico sobre o qual o revisor pode se apoiar. Neste texto, interessou-nos, no entanto, abordar essas questões a partir da discussão acerca das noções de sentido, significância e semiótico e semântico. Logo, ajuda a elucidar as competências exigidas por esse campo do saber, porque oferece ao revisor um conhecimento que lhe permite observar os elementos que constituem os textos e a ele agregam sentido, e como o mundo se constitui por meio da linguagem, dos enunciados. Como vimos, rever e retrabalhar um texto não é uma atividade linear, mas complexa e plural, a revisão não se divide em etapas que se sucedem, é uma arte que requer variados conhecimentos num esforço de diálogo e negociação.

\section{REFERENNCIAS}

BENVENISTE, É. Problemas de linguística geral I. São Paulo: Ed. Nacional, Ed. da Universidade de São Paulo, 1976.

BENVENISTE, É. Problemas de linguística geral II. Campinas, SP: Pontes, 1989.

DESSONS, G. Émile Benveniste, l'invention du discours. Paris: Press, 2006.

MESSA, R. M.; TEIXEIRA, M. Émile Benveniste: uma semântica do homem que fala. Revista Estudos da Língua(gem), Vitória da Conquista, v. 13, n. 1, p. 97-116, 2015.

NEUMANN, D. O estudo da arte da linguagem: uma questão de significação. ReVEL, edição especial n. 11, 2016. Disponível em: http://www.revel.inf.br. Acesso em: 31 mar. 2019.

SAUSSURE, F. de. Curso de linguística geral. 28. ed. São Paulo: Cultrix, 2012.

\section{(ㄷ) (1) $\circledast($}

